\title{
Actividad antibacteriana in vitro de propóleos chilenos sobre Helicobacter pylori
}

\author{
María Villanueva, Mario González, Heriberto Fernández, Myra Wilson, \\ Nimia Manquián, Carola Otth y Laura Otth
}

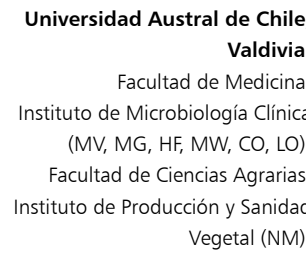

Trabajo realizado en el Instituto de Microbiología Clínica, Facultad de Medicina, Universidad Austral de Chile, Valdivia.

Los autores declaran no tener conflicto de intereses en relación a trabajo presentado

Investigación financiada por la

Dirección de Investigación de la Universidad Austral de Chile (DID) Proyecto S-2013-17

Recibido: 13 de enero de 2015 Aceptado: 28 de agosto de 2015

Correspondencia a:

Laura Otth lotth@uach.cl

\section{Introducción}

$\mathrm{E}$ 1 uso de productos naturales en medicina data de muchos siglos atrás ${ }^{1}$ y su potencial uso como nutracéuticos adquiere gran importancia en la actualidad ${ }^{2,3}$. El propóleos, sustancia natural resinosa que las abejas fabrican para la colmena, ha mostrado tener muchas aplicaciones en la medicina natural, como anestésico, anti-inflamatorio, inmuno-estimulante y anti-bacteriano, entre otras. ${ }^{4}$. Ejerce sus propiedades anti-bacterianas sobre bacterias grampositivas y gramnegativas, y su grado de actividad varía según el lugar de origen de la colmena debido a las diferentes especies vegetales que caracterizan las distintas áreas geográficas donde éstas se encuentran ${ }^{2,4-6}$.

Helicobacter pylori es una bacteria que coloniza la mucosa gástrica y se relaciona con gastritis crónica, úlcera gastro-duodenal y cáncer gástrico. La infección por $H$. pylori constituye una infección crónica extensamente difundida en la especie humana, afectando alrededor de $50 \%$ de la población mundial ${ }^{7,8}$. La erradicación de la infección por $H$. pylori contempla la administración de fármacos inhibidores de la bomba de protones asociado al uso combinado de dos antimicrobianos; los más usados son claritromicina más amoxicilina o metronidazol. Este tratamiento brinda una tasa de eficacia que fluctúa entre 70 y $80 \%$, lo que hace necesario buscar otras alternativas terapéuticas. Las fallas de la terapia se atribuyen especialmente a la adquisición de resistencia de la bacteria a los antimicrobianos comúnmente usados ${ }^{8-10}$.

Considerando la importancia de este patógeno, existen pocos estudios que caractericen el efecto inhibitorio de propóleos sobre $H$. pylori ${ }^{11}$, más aún considerando el potencial uso farmacológico e inocuidad que poseen los nutracéuticos, Boyanova y cols., han demostrado que el propóleos y sus componentes fenólicos son capaces de inhibir in vitro el desarrollo de H. pylori ${ }^{11,12}$; sin embargo, faltan estudios que complementen esta evidencia inicial.

El principal objetivo del presente estudio fue demostrar que propóleos chilenos provenientes de distintas zonas mielíferas del país tienen actividad anti-bacteriana sobre cepas de $H$. pylori y que sus características antibacterianas varían según la zona de procedencia.

\section{Material y Método}

Se evaluó la actividad anti-bacteriana de 22 propóleos sobre 10 cepas de H. pylori. Los propóleos, de orígenes botánicos diferentes, provenían de nueve de las once zonas mielíferas de Chile, abarcando desde la $\mathrm{IV}^{\circ}$ hasta la $\mathrm{X}^{\circ}$ Región y fueron obtenidos de apiarios fijos y geo-referenciados, en la época de otoño. El número de muestras por región se detalla en la Tabla 1. Los propóleos, preparados 
como extractos etanólicos al 30\%, fueron proporcionados por el Banco Nacional de Propóleos del Consorcio de Desarrollo Tecnológico Apícola de Chile, a los que se les asignó un número que identificaba su procedencia.

Las cepas de $H$. pylori estudiadas forman parte del cepario del Instituto de Microbiología Clínica de la Universidad Austral de Chile y fueron mantenidas a $-80^{\circ} \mathrm{C}$. Para el estudio fueron descongeladas y cultivadas en agar Columbia enriquecido con sangre de cordero al 5\% e Isovitalex al 1\%. El cultivo se hizo en microaerofilia, a $35^{\circ} \mathrm{C}$ por $72 \mathrm{~h}$. La pureza del cultivo se constató por la observación de bacilos gramnegativos curvos, móviles, oxidasa y ureasa positivos.

La actividad anti-bacteriana de los extractos se determinó usando el método de difusión en pocillos y de difusión en discos, descritos previamente por Boyanova y cols. ${ }^{11}$.

El inóculo se preparó suspendiendo cada cepa de $H$. pylori en caldo Mueller-Hinton, a una turbidez equivalente al tubo 2 de MacFarland.

Con el inóculo, y usando una tórula de algodón, se sembró en tres direcciones distintas una placa de agar Mueller-Hinton enriquecido con sangre de cordero al 5\% e Isovitalex al $1 \%$.

Una vez sembrada cada placa, con ayuda de un sacabocados de $7 \mathrm{~mm}$ de diámetro se hizo pocillos, los que se llenaron con 30,60 y $90 \mu \mathrm{l}$ de extracto conteniendo una concentración final de 9,18 o $27 \mathrm{mg}$ de propóleos, respectivamente. Como control se utilizó el solvente, para lo cual uno de los pocillos se llenó con $30 \mu \mathrm{l}$ de etanol al $96 \%$. Las placas se incubaron a $35^{\circ} \mathrm{C}$, en microaerofilia por $72 \mathrm{~h}$.

Para el método de difusión en discos se impregnó discos de papel filtro de $6 \mathrm{~mm}$ de diámetro con $5 \mu \mathrm{l}$ de cada extracto de propóleos al $30 \%$ en etanol $(1,5 \mathrm{mg}$ de propóleos por disco). Las placas se prepararon y sembraron igual que en el método por difusión en pocillos, colocando posteriormente los discos recién preparados conteniendo los extractos. Como control se usó discos impregnados sólo con el solvente. Las placas se incubaron a $35^{\circ} \mathrm{C}$ en microaerofilia durante $72 \mathrm{~h}$. En ambos métodos, el diámetro de la zona de inhibición se midió en $\mathrm{mm}$. Cada test se realizó en duplicado y fueron analizados mediante la prueba de varianza ANOVA (incluyendo test de Bonferroni o Dunnet) y expresados como el promedio de los valores obtenidos y su desviación estándar. Un valor $\mathrm{p}<0,05$ fue considerado estadísticamente significativo.

\section{Resultados}

El $100 \%$ de los extractos de propóleos presentó actividad anti-bacteriana sobre las 10 cepas de $H$. pylori ensayadas, tanto con el método por difusión en pocillos
(Figura 1), como con el método de difusión en discos (Figura 2). En los controles utilizando el solvente (etanol puro) no se evidenció actividad anti-bacteriana.

A pesar que todos los extractos presentaron actividad antimicrobiana, algunos extractos presentaron un mayor efecto que otros; éstos fueron analizados por separado

\begin{tabular}{|c|c|}
\hline Región & n de muestras \\
\hline IV & 1 \\
\hline V & 3 \\
\hline $\mathrm{VI}$ & 2 \\
\hline VII & 3 \\
\hline VIII & 2 \\
\hline IX & 3 \\
\hline XIV & 4 \\
\hline$x$ & 3 \\
\hline RM & 1 \\
\hline Total & 22 \\
\hline
\end{tabular}

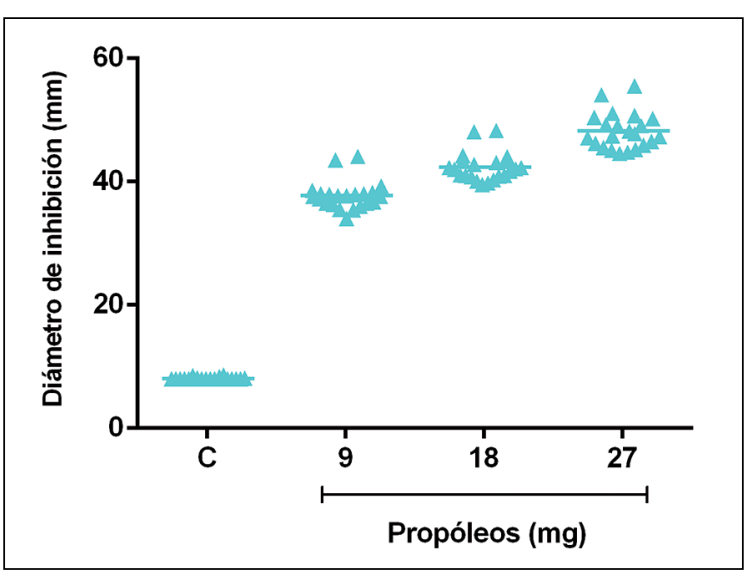

Figura 1. Valor promedio del diámetro de los halos de inhibición de 10 cepas de H. pylori frente a 22 extractos de propóleos a tres concentraciones $(9$, 18 y $27 \mathrm{mg} /$ pocillo) y etanol puro (C), usando el método de difusión en pocillos. El análisis estadístico arrojó diferencias significativas $(p<0,0001)$.

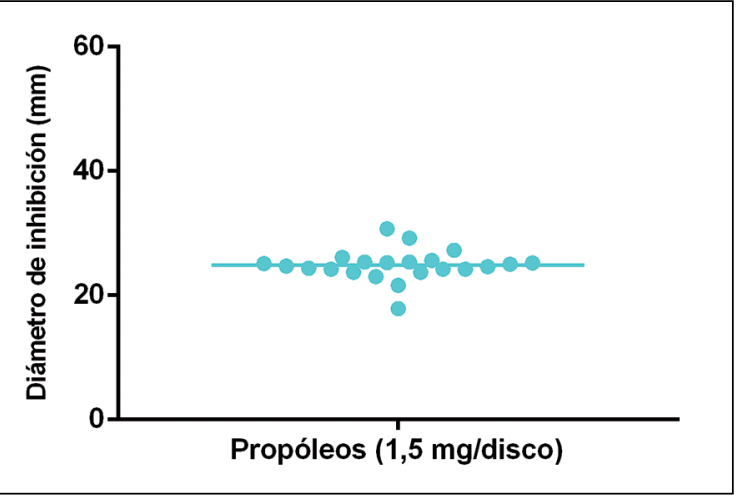

Figura 2. Valor promedio del diámetro de los halos de inhibición de 10 cepas de $H$. pylori frente a 22 extractos de propóleos, usando el método de difusión en discos impregnados con 1,5 mg de extracto. 
Figura 3. Comparación del efecto inhibitorio sobre $H$. pylori de los extractos 7,8 , 12 y 23 que presentaron valores extremos de inhibición. A: Método de difusión en pocillos llenados con $30 \mu \mathrm{l}$. B: Método de difusión en disco $\left({ }^{*} p<0,05 ;{ }^{* * *} p<0,0001\right)$.

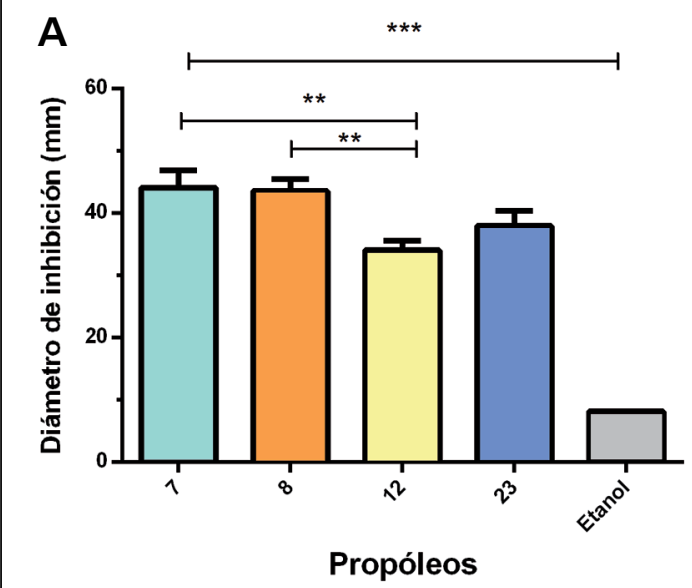

B

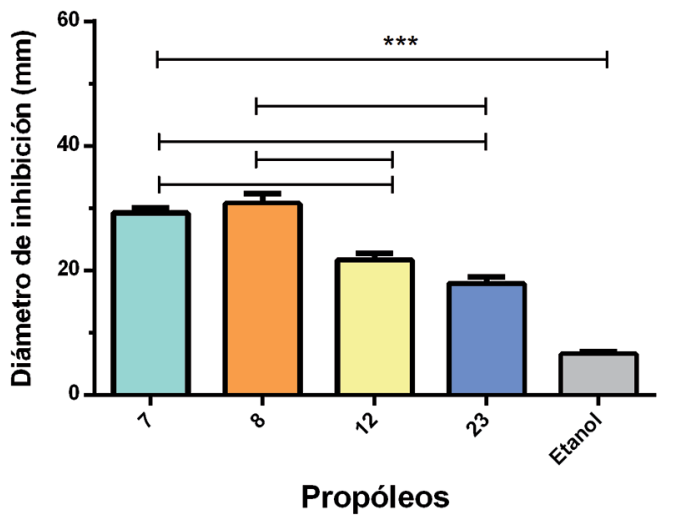

(Figura 3). Por el método de difusión en disco se obtuvieron diferencias estadísticamente significativas de superioridad en el efecto inhibitorio de los extractos 7 y 8 sobre los extractos 12 y 23 ; estas diferencias también se observaron por el método de inhibición por pocillo pero con menor significancia estadística.

\section{Discusión}

H. pylori coloniza la mucosa gástrica de más de la mitad de la población mundial y es responsable de gastritis crónica, úlcera péptica, adenocarcinoma y linfoma asociado a la mucosa gástrica ${ }^{7,10}$. El tratamiento convencional sólo logra entre 70 y $80 \%$ de éxito en la cura de los pacientes, por lo que se busca activamente alternativas terapéuticas distintas a los antimicrobianos, como vacunas, probióticos, inactivación fotodinámica, fagoterapia y búsqueda de productos fitoterapéuticos o nutracéuticos ${ }^{8-10,13-16}$.

Entre las alternativas fitoterapéuticas, destaca el potencial uso de los extractos de propóleos, que están constituidos por flavonoides, ácidos fenólicos y sus ésteres, además de una gran variedad de otros compuestos cuya presencia y cantidad varía según el lugar de obtención ${ }^{1,2}$. Los extractos de propóleos han demostrado actividad antibacteriana sobre especies grampositivas y gramnegativas, así como sobre levaduras y virus ${ }^{2}$.

Los resultados obtenidos en el presente estudio mostraron que $100 \%$ de los extractos de propóleos obtenidos de distintos lugares geográficos de Chile presentaron actividad inhibitoria sobre las cepas de $H$. pylori ensayadas, lo que fue evidenciado por ambos métodos para determinar efecto inhibitorio.

Con el método de difusión en pocillos los diámetros de los halos de inhibición fluctuaron entre 35 y $72 \mathrm{~mm}, 31$ y $60 \mathrm{~mm}$ y 26 y $54 \mathrm{~mm}$, en los pocillos conteniendo 27 , 18 y $9 \mathrm{mg}$ de propóleos, respectivamente, en tanto que en los controles con el solvente, etanol puro, los diámetros obtenidos fluctuaron entre 7 y $11 \mathrm{~mm}$.

Estos resultados son superiores a los obtenidos por Boyanova y cols. ${ }^{11}$, con este método, quienes encontraron 13,8 y $7,2 \%$ de cepas resistentes a 9 y $18 \mathrm{mg}$ extracto, respectivamente. Con el mismo método, $100 \%$ de las cepas analizadas presentó halos de inhibición superiores a $15 \mathrm{~mm}$, en comparación con los resultados de Boyanova y cols. ${ }^{11}$, quienes reportan que 48,$9 ; 52,2$ y $77,8 \%$ de sus cepas presentaron halos de inhibición iguales o superiores a $15 \mathrm{~mm}$ de diámetro frente a 9,18 y $27 \mathrm{mg}$ de propóleos, respectivamente.

Con el método de difusión en disco, los diámetros de los halos de inhibición fluctuaron entre 15 y $31 \mathrm{~mm}$, en relación al control en que se obtuvo halos entre los 6 y 8 mm. Boyanova y cols. ${ }^{11}$, reportaron $7,9 \%$ de cepas resistentes con este método, y $60,3 \%$ de sus cepas presentan halos de inhibición iguales o superiores a $15 \mathrm{~mm}$.

Nostro y cols. ${ }^{14}$, determinaron las concentraciones inhibitorias mínimas (CIM) de un extracto acuoso y etanólico de propóleos sobre 12 cepas de H. pylori, obteniendo CIM que fluctuaron entre 0,075 y $0,3 \mathrm{mg} / \mathrm{ml}$ con el extracto etanólico y entre 0,6 y $2,5 \mathrm{mg} / \mathrm{ml}$ con el extracto acuoso. La mayor actividad anti-bacteriana de los extractos etanólicos por sobre los acuosos también ha sido demostrada por Carrillo y cols. ${ }^{6}$.

Además, por el método de difusión en disco fue posible identificar de mejor manera la superioridad de dos extractos de propóleos ( 7 y 8 ) frente a los dos extractos que presentaron una menor capacidad inhibitoria (12 y 23). Esto puede deberse a las diferentes concentraciones de propóleos utilizadas por cada método. Los extractos que presentaron mayor actividad provenían de la V Región, en tanto que los con menor actividad provenían de la VI 
y X regiones de Chile. Considerando que los propóleos fueron de diferentes orígenes botánicos y geográficos, es posible esperar que exista diferencia en sus composiciones químicas, lo que podría explicar las diferencias observadas. Ello hace necesario caracterizar los propóleos y establecer sus principios activos.

Aunque los datos obtenidos in vitro en el presente estudio muestran una efectiva actividad anti $H$. pylori de los propóleos chilenos, es necesario realizar estudios adicionales, tanto microbiológicos como farmacológicos para avanzar en una posible utilidad clínica de estos productos naturales.

Agradecimientos. Los autores agradecen al Banco Nacional de Propóleos del Consorcio de Desarrollo Tecnológico Apícola de Chile por proporcionar las muestras de propóleos.

\section{Resumen}

Introducción: El propóleos es un producto natural derivado de la apicultura que tiene propiedades anes- tésicas, anti-inflamatorias, inmuno-estimulantes y antibacterianas. Ejerce su acción sobre distintas bacterias grampositivas y gramnegativas. Sin embargo, es muy poco lo que se sabe en relación a su actividad sobre $H$. pylori, bacteria asociada con gastritis crónica, úlcera gastro-duodenal y cáncer gástrico y que coloniza a alrededor de la mitad de la población mundial. Objetivo: Evaluar la actividad inhibitoria de 22 extractos de propóleos de orígenes botánicos diferentes, provenientes de nueve de las once zonas mielíferas de Chile, en la época de otoño, sobre 10 cepas de $H$. pylori aisladas de mucosa gástrica. Metodología: La actividad antibacteriana de los extractos se determinó a través del método de difusión en pocillos y de difusión en discos. Resultados: 100\% de los extractos fueron activos sobre las cepas ensayadas, observándose halos de inhibición iguales o mayores a $15 \mathrm{~mm}$ en ambos métodos. Conclusiones: Los datos obtenidos in vitro en el presente estudio muestran una efectiva actividad anti H. pylori de los propóleos chilenos, siendo necesario estudios microbiológicos y farmacológicos adicionales para avanzar en una posible utilidad clínica de estos productos naturales.

\section{Referencias bibliográficas}

1.- Manrique A. Actividad antimicrobiana de propóleos provenientes de dos zonas climáticas del estado Miranda, Venezuela. Efecto de la variación estacional. Zootecnia Trop 2006; 24 : 43-53.

2.- Farré R, Frasquet I, Sánchez A. El própolis y la salud. Ars Pharm 2004; 45: 21-43.

3.- Pérez J, Isaza G, Acosta S. Actividad antibacteriana de extractos de Phenaxrugosus y Tabebuiachrysantha. Biosalud 2007; 6: 59-68.

4.- Fatoni A, Artika I, Hasan A, Kuswandi. Antibacterial activity of propolis produced by Trigonaspp. against Campylobacter spp. HAYATY J Biosci 2008; 15: 161-4.

5.- Peña R. Estandarización en propóleos: antecedentes químicos y biológicos. Cien Invest Agr 2008; 35: 17-26.

6.- Carrillo M, Castillo L y Mauricio R. Evaluación de la actividad antimicrobiana de extractos de propóleos de la Huasteca Potosina (México). Inf Tecnol 2011; 22: 21-8.

7.- Altman E, Fernández H, Chandan V, Harrison B, Wilson M, Otth L, et al. Analysis of
Helicobacter pylori isolates from Chile: occurrence of selective type 1 Lewis $b$ antigen expression in lipopolysaccharide. $\mathrm{J}$ Med Microbiol 2008; 57: 585-91.

8.- Vale F, Oleastro M. Overview of the phytomedicine approaches against Helicobacter pylori. World J Gastroenterol 2014; 20: 5594609

9.- Gisbert J, Calvet X. Review article: the effectiveness of standard triple therapy for Helicobacter pylori has not changed over the last decade, but it is not good enough. Aliment Pharmacol Ther 2011; 34: 1255-68.

10.- Pastene E, Hebel S, García A. Polifenoles con efecto anti-Helicobacter pylori: fuentes de obtención y su potencial utilización en fitomedicamentos, nutracéuticos y alimentos funcionales. Rev Farmacol Chile 2012; 5: 3550.

11.- Boyanova L, Gergova G, Nikolov R, Derejian S, Lazarova E, Katsarov N, et al. Activity of Bulgarian propolis against 94 Helicobacter pylori strains in vitro by agar-well diffusion, agar dilution and disc diffusion methods. J Med Microbiol 2005; 54: 481-3.
12.- Boyanova L, Derejian S, Koumanova R, Katsarov N, Gergova G, Mitov I, et al. Inhibition of Helicobacter pylori growth in vitro by Bulgarian propolis: preliminary report. J Med Microbiol 2003; 52: 417-9.

13.- Coelho L, Bastos E, Resende C, Paula e Silva C, Sanches B, de Castro F, et al. Brazilian green propolis on Helicobacter pylori infection. A pilot clinical study. Helicobacter 2007; 12: 572 4.

14.- Nostro A, Cellini L, Di Bartolomeo S, Di Campli E, Grande R, Cannatelli M, et al. Antibacterial effect of plant extracts against Helicobacter pylori. Phytother Res 2005; 19 : 198-202.

15.- Nostro A, Cellini L, Di BartolomeoS, Cannatelli M, Di Campli E, Procopio F, et al. Effects of combining extracts (from Propolis or Zingiberofficinale) with clarithromycin on Helicobacter pylori. Physiother Res 2006; 20: 187-90.

16.- Ustün O, Ozcelik B, Akyön Y, Abbasoglu U, Yesilada E. Flavonoids with anti-Helicobacter pylori activity from Cistus laurifolius leaves. J Ethnopharmacol 2006; 108: 457-61. 